\title{
Functional and Morphological Studies of Organic and Inorganic Tomatoes
}

\author{
Shwetha M S, Sinija V R*, M Durgadevi , B K Yadav, and S Shanmugasundaram
}

\section{Shwetha Manchanabele Shankar, Sinija Vadak- kepulppara Ramachan- dran Nair*, Manoharan Duragdevi, Binod Kumar Yadav and Shanmugasun- daram Saravanan Indian Institute of Food Processing Technology, Thanjavur, Tamil Nadu, India \\ Correspondence \\ Sinija V R,}

Associate Professor and Head, Department of Planning and Monitoring Cell and Food Processing Business Incubation Centre, Indian Institute of Food Processing Technology, Thanjavur, Tamil Nadu, INDIA

Phone No: +9750968421

E-mail: sinija@iifpt.edu.in

\section{History}

- Submission Date: 17-01-2018;

- Revised Date: 06-03-2018

- Accepted Date: 03-05-2018

\section{DOI : 10.5530/pj.2018.4.119}

Article Available online

http://www.phcogj.com/v10/i4

\section{Copyright}

(C) 2018 Phcog.Net. This is an openaccess article distributed under the terms of the Creative Commons Attribution 4.0 International license.

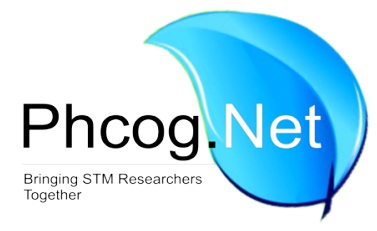

\begin{abstract}
Aim: To study the functional and morphological characteristics of organic and inorganic tomatoes. Methodology: UV treated, and untreated organic and inorganic tomato powdered samples were assessed using an analytical technique FT-IR and SEM. Results: FT-IR spectra of organic control samples showed peaks at $\left(3290.12,2924.72\right.$ and $\left.1611.61 \mathrm{~cm}^{-1}\right)$ while, organic treated samples revealed some peaks at $\left(3287.11,2925.66\right.$ and $1612.91 \mathrm{~cm}^{-1}$ ), inorganic control tomatoes confirmed the peaks at $\left(3289.47,2925.76\right.$ and $\left.1619.26 \mathrm{~cm}^{-1}\right)$ and in inorganic treated tomatoes peaks was at $\left(3289.42,2925.34\right.$ and $\left.1619.31 \mathrm{~cm}^{-1}\right)$ respectively, on confirming the presence of $\mathrm{O}-\mathrm{H}, \mathrm{C}-\mathrm{H}, \mathrm{C}=\mathrm{C}, \mathrm{C}=\mathrm{O}$ and $\mathrm{C}-\mathrm{OH}$ functional groups. However, results confirmed slight changes in functional groups of organic and inorganic samples and UV treatment helps in decreasing the effect of fluoride, chloride and other synthetic chemicals level by disinfecting the samples. SEM micrographs showed non-significant changes with minimal effect of UV in all samples. Conclusion: The outcome of the study helps in effective understanding of functional and microstructural differences between organic and inorganic tomatoes.

Key words: Organic, Inorganic, Tomatoes, UV treatment, FT-IR, SEM.
\end{abstract}

\section{INTRODUCTION}

Tomato is an important source of micronutrients, minerals like potassium and carboxylic acids, including ascorbic, citric, malic, fumaric and oxalic acids. ${ }^{1,2}$ Recent epidemiological studies have suggested that the consumption of tomatoes and tomato-based food products helps in reducing the risk of cardiovascular disease and cancer (oral cavity, pharynx, esophagus, stomach, rectum, colon, urinary bladder, prostate and breast) in humans as reported by, $3,4,5$ and this protective effect has been attributed to carotenoids, in particular lycopene and phenolic compounds which are considered as one of the major classes of phytochemicals in this fruit. ${ }^{6}$ As we know carotenoids are a family of compounds of over 600 fat-soluble plant pigments that provide much of the color we see in nature, by facilitating important nutritional benefits to human population owing to their pro vitamin $\mathrm{A}$ and antioxidant activities.?

Increasing demand and interest towards organically grown fruits and vegetables and its products imposed the need to study the quality and nutritional differences between organic and inorganic tomatoes. Some studies have shown higher number of bioactive compounds in organically produced tomatoes compared to conventional, ${ }^{8,9,10}$ and are often linked in protecting the environment and having better quality in terms of taste with enhanced storage period.
Ultra Violet (UV) radiation is a surface sterilization treatment for increasing shelf life of fruits and vegetables that are highly susceptible to microbial spoilage. UV radiation is a promising non-thermal preservation method classified into UV-A (315-400 $\mathrm{nm})$, UV-B (280-315 nm) and UV-C (200-280 nm) respectively. UV-C has the germicidal effect since it inactivates the microorganisms. ${ }^{11}$ Fresh fruits and vegetables exposed to low doses of UV induces antifungal compounds and delays ripening there by enhancing shelf-life.

Functional groups are specific group of atoms or bonds present within the molecules which are responsible for the characteristic chemical reactions of those molecules. The fresh and processed tomatoes contain volatile compounds falls under various chemical classes like ketones, aldehydes, alcohols, esters, ethers, hydro- carbons, sulfur, nitrogen and oxygen compounds, phenols, oxygen-containing heterocyclic compounds, free acids and lactones. ${ }^{12}$ FTIR is a powerful technique that can be used to obtain an infrared spectrum of absorption or emission of all states of matter (solid, liquid and gas). The morphological study becomes important in knowing the form and structure of any food material that can be achieved with the help of SEM. The present study focusses on analyzing and comparing 
the functional group and morphological differences between organic and inorganic tomatoes before and after UV treatment by using FTIR and SEM.

\section{MATERIALS AND METHODS}

\section{Sample collection}

Freshly harvested riped organic and inorganic tomatoes (Variety: Sivam) were procured from Coimbatore and Thanjavur, Tamil Nadu, India. Every effort was made in maintaining the quality of samples throughout the supply chain.

\section{Preparation of sample \\ UV treatment and tray drying}

A laboratory model of continuous UV-C system was used for the experiment consisting of conveying system, treatment chamber, control system and holding frame. Fresh tomato samples were subjected to UV treatment for $10-15 \mathrm{~min}(8 \times 15 \mathrm{~W})$. Treated and untreated organic and inorganic tomato samples was sliced to $6-8 \mathrm{~mm}$ thickness and subjected to tray drying at $50^{\circ} \mathrm{C}$ for $14-16 \mathrm{hrs}$. Further, the dried slices were processed into fine powder by using a blender and passed through different sieves to achieve uniform particle size.

\section{Bio-chemical analysis}

Organic and inorganic tomatoes were analyzed for bio-chemical properties like $\mathrm{pH}$ ( $\mathrm{pH}$ meter), TSS (Refractometer), titratable acidity, vitamin $\mathrm{C}$ and lycopene by standard protocols. ${ }^{13,14}$

Table1: Bio-chemical composition of organic and inorganic tomatoes.

\begin{tabular}{cccc}
\hline SI. No & Component & Organic tomatoes & Inorganic tomatoes \\
\hline 1 & $\mathrm{pH}$ & $4.2 \pm 0.05$ & $4.5 \pm 0.05$ \\
2 & TSS ( ${ }^{\circ}$ Brix) & $4.7 \pm 0.05$ & $4.1 \pm 0.00$ \\
3 & Titratable acidity (\%) & $0.38 \pm 0.01$ & $0.43 \pm 0.01$ \\
4 & Vitamin C (mg/100g) & $22.5 \pm 0.10$ & $20.2 \pm 0.28$ \\
5 & Lycopene (mg/100g) & $4.13 \pm 0.15$ & $3.35 \pm 0.01$ \\
\hline
\end{tabular}

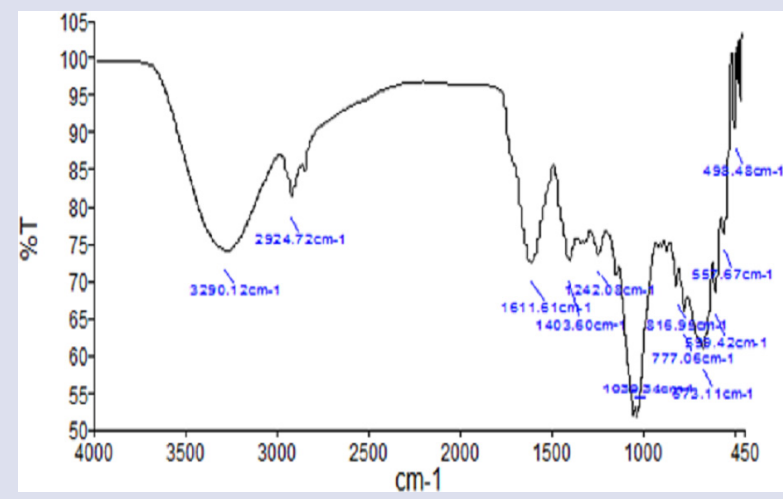

Figure 1: FT-IR spectrum for organic untreated tomato powder.

\section{Functional group analysis}

Fourier transform infrared spectrophotometer is an important tool for identifying the presence of different types of chemical bonds (functional groups) present in compounds. Dried powders of different sample specimen were loaded in FTIR Spectroscope by taking a small quantity to know the presence of functional groups in tomatoes (Shimadzu, IR Affinity1, Japan), with a scan range from 400 to $4000 \mathrm{~cm}^{-1}$ with a resolution of $4 \mathrm{~cm}^{-1}$ respectively.

\section{Morphological analysis}

The microstructure of the tray dried organic and inorganic (control and treated) tomato samples were investigated using a normal scanning electron microscope (SEM, VEGA3 TESCAN).

\section{RESULTS AND DISCUSSIONS}

\section{Bio-chemical analysis}

Quality attributes of fresh organic and inorganic tomatoes are presented in Table 1. Organic samples showed better results on confirming TSS (4.7 ${ }^{\circ}$ Brix), vitamin C (22.5 mg/100g), lycopene $(4.13 \mathrm{mg} / 100 \mathrm{~g})$, with reduced acidity $(0.38 \%)$, pH was (4.2) indicating samples were more acidic. Whereas, inorganic tomatoes exhibited decreased amount of TSS, vitamin C and lycopene (4.1 ${ }^{\circ}$ Brix, $\left.20.2 \mathrm{mg} / 100 \mathrm{~g}, 3.35 \mathrm{mg} / 100 \mathrm{~g}\right)$, with increasing in acidity $(0.43 \%)$.

Table 2: FTIR spectra $\left(\mathrm{cm}^{-1}\right)$ for UV treated and untreated organic and inorganic tomatoes.

\begin{tabular}{cccccc}
\hline SI. No & \multirow{2}{*}{$\begin{array}{c}\text { Functional } \\
\text { group }\end{array}$} & \multicolumn{2}{c}{ Organic samples } & \multicolumn{2}{c}{ Inorganic samples } \\
\cline { 3 - 6 } & & Control & Treated & Control & Treated \\
\hline 1 & O-H stretch & 3290.12 & 3287.11 & 3289.47 & 3289.42 \\
2 & C-H stretch & 2924.72 & 2925.66 & 2925.76 & 2925.34 \\
3 & C=C and C=O & 1611.61 & 1612.91 & 1619.26 & 1619.31 \\
4 & C=C & 1403.6 & 1402.74 & 1407.24 & 1406.29 \\
5 & C-F & - & - & 1315.15 & 1244.06 \\
6 & C-OH stretch & 1039.34 & 1041.36 & 1036.08 & 1035.35 \\
\hline
\end{tabular}

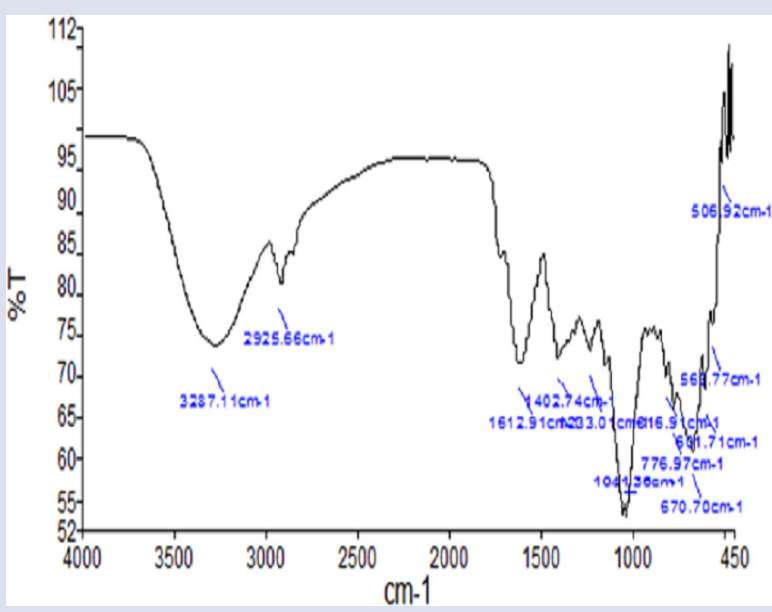

Figure 2: FT-IR spectrum for organic treated tomato powder. 


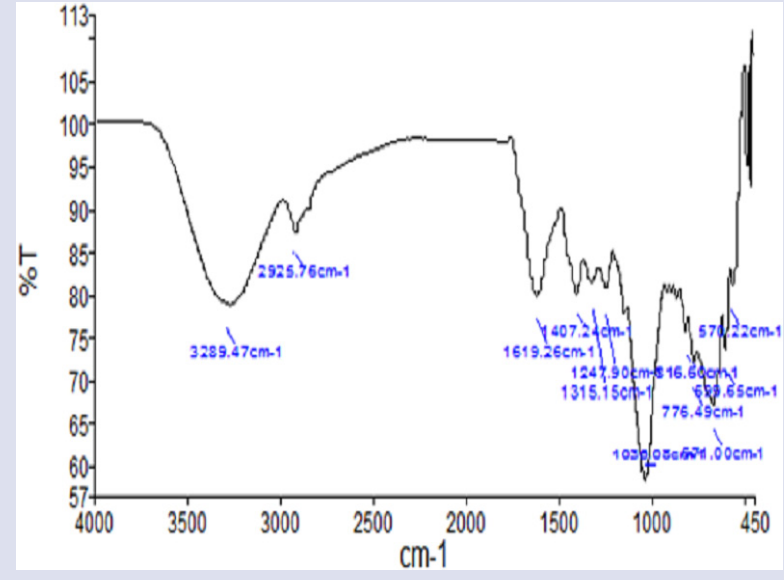

Figure 3: FT-IR spectrum for inorganic untreated tomato powder.

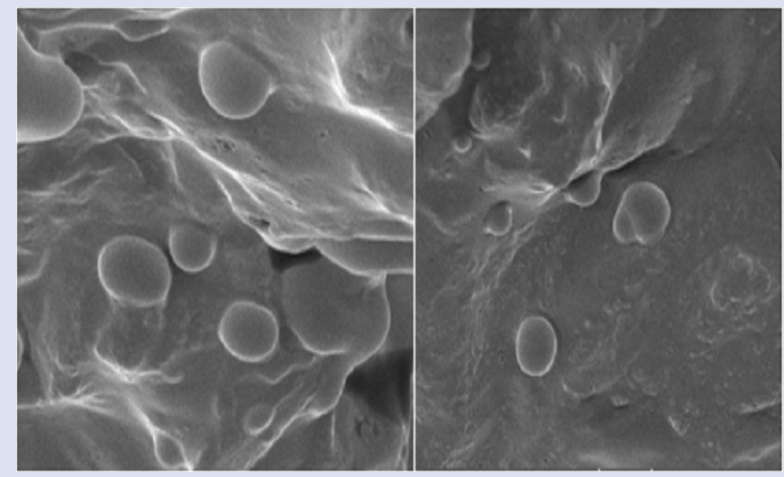

Figure 5: SEM micrograph for untreated organic tomato sample.

\section{Fourier transforms infrared spectroscopy (FTIR)}

The FTIR spectroscopy was used to identify the functional groups of the active components present in organic and inorganic tray dried tomato powder in both control and UV treated condition based on the peak values in the region of IR radiation. The peak values of FTIR in all samples confirmed the presence $\mathrm{O}-\mathrm{H}$ stretching, $\mathrm{C}-\mathrm{H}$ stretching, $\mathrm{C}=\mathrm{O}$, $\mathrm{C}=\mathrm{C}$ and $\mathrm{C}-\mathrm{OH}$ groups respectively.

The study showed organic and inorganic tomato samples (control and treated), exhibited more or less same functional groups with considerable differences in peak values (Table 2 and Figure 1 to 4 ) which may be due to application of various pesticides, insecticides, fertilizers and other artificial chemicals, water source, soil condition and other residual effects in inorganic samples which varies in organic samples where some naturally occurring biological materials are used that influences direct or indirect changes in the functional groups. The presence of C-F group in inorganic untreated samples was found to be reduced considerably in UV treatment. Water treatment plants uses UV to disinfect water without any chemicals because of which taste, and other composition present may vary. Henceforth, UV showed positive results by retaining all functional compounds without losses.

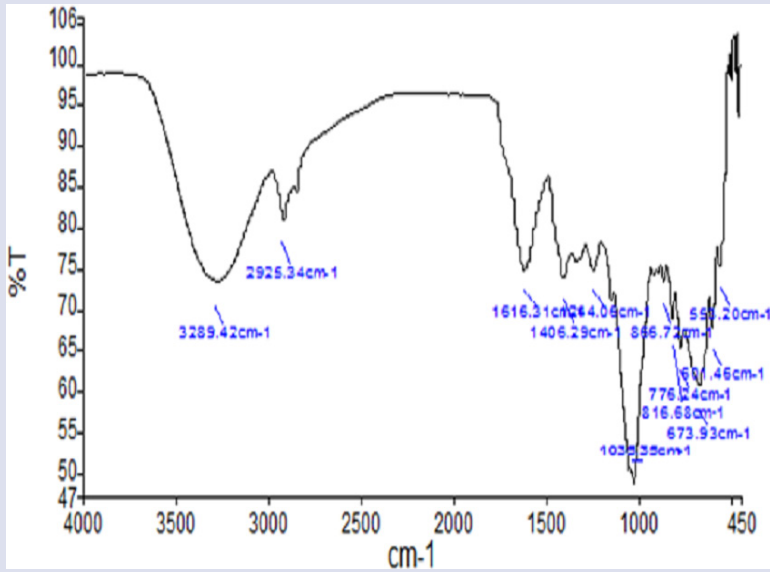

Figure 4: FT-IR spectrum for inorganic treated tomato powder.

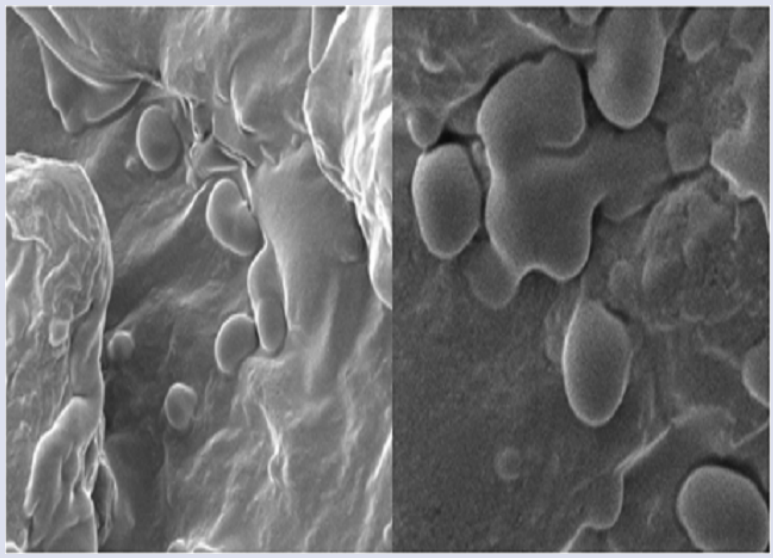

Figure 6: SEM micrograph for treated organic tomato sample.

FTIR spectra showed peak values at a $3290.12,2924.72,1611.61$ and $1403.6 \mathrm{~cm}^{-1}$ in organic untreated, 3287.11, 2925.66, 1612.91 and 1402. $74 \mathrm{~cm}^{-1}$ in organic treated, 3289.47, 2925.76, 1619.26, $1407.24 \mathrm{~cm}^{-1}$ in inorganic untreated and 3289.42, 2925.34, 1616.31 and $1406.29 \mathrm{~cm}^{-1}$ in inorganic treated samples. The analyzed peak value results were found comparable with ${ }^{15,16}$ respectively. IR spectrum between 3100 and 3600 indicates the presence of It was evident that tomatoes are rich in alcohols, phenols (phenolic acids and flavonoids), carboxylic acids (amino acids), amides, alkynes and alkenes, henceforth, considered as a health promoter.

\section{Scanning Electron Microscopy (SEM)}

The morphological changes of organic and inorganic treated, and untreated tomato powder were investigated by using Scanning Electron Microscope (Figure 5 to 8 ). The results of the work reveal no significant/ distinctive changes in both treated and untreated organic and inorganic samples. The surface structure of the images was almost similar in all cases; however, the effect of UV treatment was found to have a minimal effect on the structural changes of the tomato powder. Micrographs exhibited quite sticky surface with few spherical and elongated particles which may be due presence of moisture. Similar observations were 


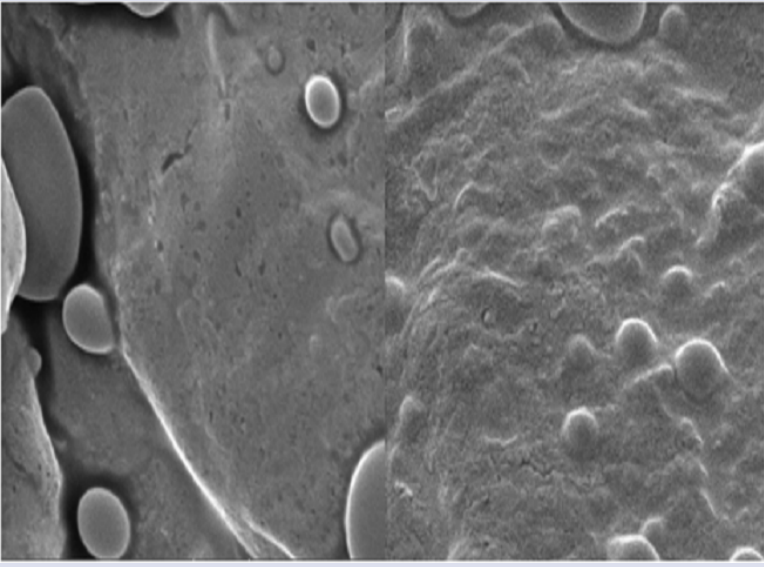

Figure 7: SEM micrograph for untreated inorganic tomato sample.

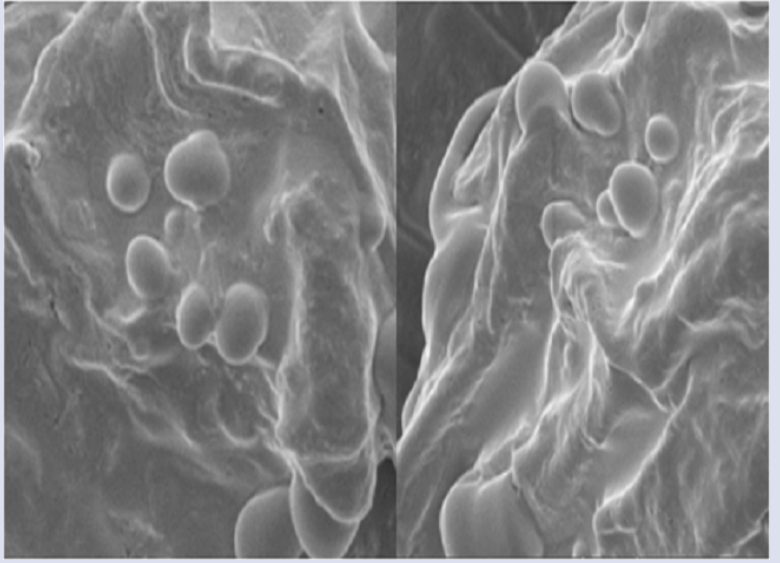

Figure 8: SEM micrograph for treated inorganic tomato sample. noticed by, ${ }^{17}$ on reporting the temperature and moisture content effects on cohesion and flow ability of dairy powder. Reports also showed some caking phenomena in tomato powder which is time-temperature dependent. ${ }^{18}$

\section{CONCLUSION}

FTIR and SEM are well-established simple, sensitive, non-destructive technique that helps in rapid determination of functional groups and morphology in agricultural food products with accuracy. The results of the study showed the presence of strong and broad absorption bands of water, alcohols, phenols and carboxylic acids along with alkenes and amide $(\mathrm{O}-\mathrm{H}, \mathrm{C}-\mathrm{H}, \mathrm{C}=\mathrm{O}, \mathrm{C}=\mathrm{C}$ and $\mathrm{C}-\mathrm{OH})$ at higher peaks respectively. Functional groups help in knowing the quality properties of tomatoes that need to be taken care right from farm to fork and offers a platform in understanding organic and inorganic tomatoes subjected to various processing conditions respectively. In SEM analysis distinctive changes were not observed and concludes presence of moisture content, treatments, drying temperature and uniformity in particle size, variety are deciding factors that influences morphological changes in tomatoes.

\section{ACKNOWLEDGEMENT}

The authors are thankful to Council of Scientific and Industrial Research (CSIR), New Delhi, India for funding this project.

\section{ABBREVIATIONS}

FT-IR: Fourier Transform- Infrared, SEM: Scanning Electron Microscope; UV: Ultra Violet.

\section{CONFLICT OF INTEREST}

There are no conflicts of interest.

\section{REFERENCES}

1. Caputo M, Sommella MG, Graciani G, Giordano I, Fogliano V, Porta R, Mariniello L. Antioxidant profiles of corbara small tomatoes during ripening and effects of aqueous extracts on j-774 cell antioxidant enzymes. Journal of Food Biochemistry. 2004;28(1):1-20.
2. Suarez MH, Rodriyguez ER, Romero CD. Mineral and trace element concentrations in cultivars of tomatoes. Food Chemistry. 2006;104(2):489-99.

3. Ferreira AL, Yeum KJ, Liu C, Smith D, Krinsky NI, Wang XD, Russell RM. Tissue distribution of lycopene in ferrets and rats after lycopene supplementation. Journal of. Nutrition. 2000;130(5):1256-60.

4. Tang FY, Shin CJ, Cheng LH, Ho HJ, Chen HJ. Lycopene inhibits growth of human colon cancer cells via suppression of the Akt signaling pathway. Mol. Nutr. Food Res. 2008;52(6):646-54.

5. Vaishampayan U, Hussain M, Banerjee M, Seren S, Sarkar FH, Fontana J et al. Lycopene and soy isoflavones in the treatment of prostate cancer. Nutr. Cancer. 2007;59(1):1-7.

6. Khachik F, Carvalho L, Bernstein PS, Muir GI, Zhao DY, Katz NB. Chemistry, distribution, and metabolism of tomato carotenoids and their impact on human health. Exp. Biol. Med. 2002;227(10):845-51.

7. Krinsky $\mathrm{NI}$, Johnson EJ. Carotenoid actions and their relation to health and disease. Mol. Aspects Med. 2005; 26(6):459-516.

8. Rembialkowska E. The impact of organic agriculture on food quality. Agricultura. 2004;3:19-26

9. Ordonez-Santos LE, Vazquez-Oderiz ML, Romero-Rodryguez MA. Micronutrient contents in organic and conventional tomatoes (Solanum lycopersicum L.). International Journal of Food Science and Technology. 2011;46(8):1561-8.

10. Chassy AW, Bui L, Renaud EN, Horn MV, Mitchell AE. Three-year comparison of the content of antioxidant microconstituents and several quality characteristics in organic and conventionally managed tomatoes and bell peppers. Journal of Agricultural and Food Chemistry. 2006;54(21):8244-52.

11. Bolton JR, Linden KG. Standardization of methods for fluence (UV dose) determination in bench-scale UV experiments. Journal of Environmental Engineering. 2003;12(3):209-15.

12. Linforth RST, Savary I, Pattenden B, Taylor AJ. Volatile compounds found in expired air during eating of fresh tomatoes and in the headspace above tomatoes. J Sci Food and Agric. 1994;65(2):241-47.

13. Ranganna S. In: Manual of Analysis of Fruits and Vegetable Products. McGraw Hill, New Delhi. 1976;77.

14. Ranganna S. Handbook of Analysis and Quality Control of Fruit and Vegetable Products. 2nd Ed: Tata McGraw-Hill Pub. Co. Ltd., New Delhi. 1986;931-2.

15. Mohie M Kamil, Gamal F Mohamed, Mohamed S Shaheen. Fourier Transformer Infrared Spectroscopy for Quality Assurance of Tomato Products. Journal of American Science. 2011;7(6):559-72.

16. Bunghez IR, Raduly M, Doncea S, Aksahin I, Ion RM. Lycopene determination in tomatoes by different spectral techniques (UV-VIS, FTIR AND HPLC). Digest Journal of Nanomaterials and Biostructures. 2011;6(3):1349-56.

17. Rennie PR, Chen XD, Hargreaves $C$, Mackereth AR. A study of the cohesion of dairy powders, Journal of Food Engineering. 1999;39(3):277-84.

18. Fengxia Liu, Xiamin Cao, Wang H, Liao X. Changes of tomato powder qualities during storage. Powder Technology. 2010;204(1):159-66.

Cite this article: Shwetha MS, Sinija VR, Durgadevi M, BK Yadav, Shanmugasundaram S. Functional and Morphological Studies of Organic and Inorganic Tomatoes. Pharmacog J. 2018;10(4):715-9. 
GRAPHICAL ABSTRACT
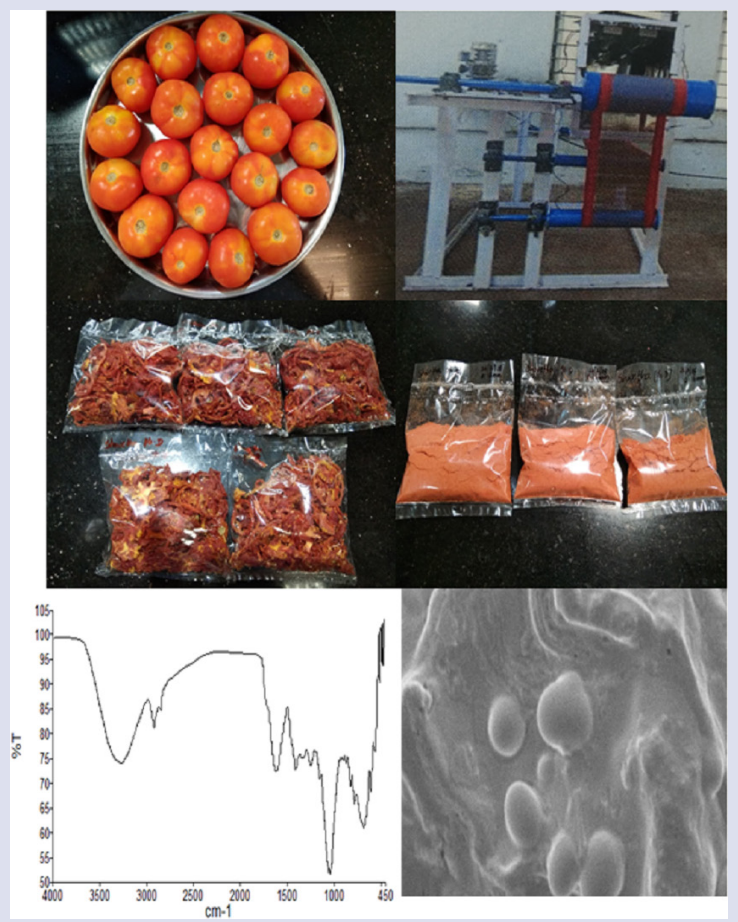

\section{SUMMARY}

- Tomato is considered as "protective foods" because of its special nutritive values which are very low in fat and have zero cholesterol level, with an excellent source of lycopene, carotene, anthocyanin, antioxidants, dietary fiber, minerals, and vitamins.

- The therapeutic properties of tomatoes (antioxidants) scientifically proved to be effective in fighting against cancers, including colon, prostate, breast, endometrial, lung, and pancreatic tumors.

- The present work has been performed to establish the various FTIR and SEM parameters, which creates a better platform in understanding and judging functional and structural changes between organic and inorganic tomatoes and role of UV by creating a commercial interest among farmers, processors and consumers.

\section{ABOUT AUTHORS}

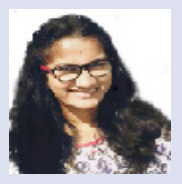

Er. Shwetha M S, Ph. D Scholar in Food Process Engineering, Indian Institute of Food Processing Technology, Thanjavur, Tamil Nadu, India.

Dr. Sinija V R, Associate Professor and Head, Department of Planning and Monitoring Cell and Food Processing Business Incubation Centre, Indian Institute of Food Processing Technology, Thanjavur, Tamil Nadu, India.

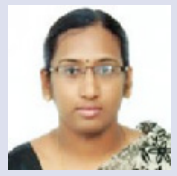

Dr. M. Durgadevi, Assistant Professor, Department of Food Processing Business Incubation Centre, Indian Institute of Food Processing Technology, Thanjavur, Tamil Nadu, India.

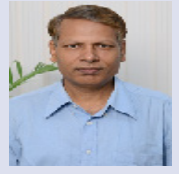

Dr. B.K Yadav, Associate Professor and Head, Department of Food Packaging and System Development, Indian Institute of Food Processing Technology, Thanjavur, Tamil Nadu, India.

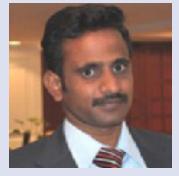

Dr. S Shanmugasundaram, Associate Professor and Head, Department of Academics and Human Resource Development, Indian Institute of Food Processing Technology, Thanjavur, Tamil Nadu, India. 